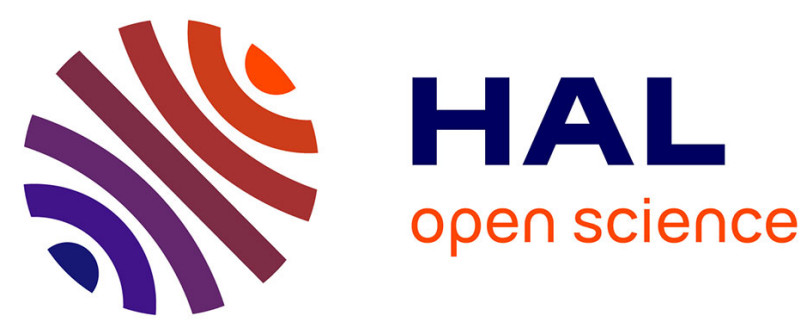

\title{
Analysis and modelling of the role of temperature in the static forward characteristics of an IGBT
}

Layachi Boussouar, Hervé Morel, Bruno Allard, Cyril Buttay

\section{To cite this version:}

Layachi Boussouar, Hervé Morel, Bruno Allard, Cyril Buttay. Analysis and modelling of the role of temperature in the static forward characteristics of an IGBT. International Journal of Power Electronics, 2019, 10 (3), pp.187. 10.1504/ijpelec.2019.099337 . hal-02121811

\section{HAL Id: hal-02121811 \\ https://hal.science/hal-02121811}

Submitted on 6 May 2019

HAL is a multi-disciplinary open access archive for the deposit and dissemination of scientific research documents, whether they are published or not. The documents may come from teaching and research institutions in France or abroad, or from public or private research centers.
L'archive ouverte pluridisciplinaire HAL, est destinée au dépôt et à la diffusion de documents scientifiques de niveau recherche, publiés ou non, émanant des établissements d'enseignement et de recherche français ou étrangers, des laboratoires publics ou privés. 


\title{
Analysis and Modeling of the Role of Temperature in the Static Forward Characteristics of an IGBT
}

\author{
L. Boussouar ${ }^{* * *}$, H. Morel ${ }^{*}$, B. Allard", C. Buttay ${ }^{*}$ \\ ** Université Ferhat Abas, Sétif, Algerie, Lab. MPA, IOMP \\ * Université de Lyon, INSA Lyon, CNRS, Lab. Ampère
}

lboussouar@gmail.com

\begin{abstract}
To effectively simulate the electrical characteristics of an IGBT, it is necessary to have a good model for applications operating in a wide range of temperatures. A new model of the on-state forward characteristics of an IGBT was developed and validated in MAST language in static mode using the SABER simulator. A particular attention was given to temperature dependence, based on the physical analysis of semiconductor device regions and the use of local and physic-based relations. The model was compared to experimental results and to the standard Hefner model. The validation of the model shows a good agreement between measurements and simulation. A clear improvement in the accuracy of the onstate characteristic temperature dependence with the was obtained.
\end{abstract}

\section{Keywords:}

IGBT, MOSFET; Modeling, Power semiconductor devices, Power transistors and Simulation.

\section{Introduction}

Since the invention of the insulated-gate bipolar transistor (IGBT), most of the models published in the literature have been based on Hefner's model [1] , which describes a bipolar transistor (BJT) controlled by a MOSFET transistor. However, the static forward characteristics predicted using this model is not in good agreement with experimental measurements when the temperature varies. In this paper a new analytical model is presented, based on a multiphysics analysis of the different semiconductor regions located along the flow lines of the holes and the electrons. This model is based on the same principles as the Hefner's model but it improves the multiphysics analysis of each element of the model with a better temperature dependence analysis with respect to the local semiconductor regions. Section II presents a short state-of-the art of the IGBT modeling, then in section III, the principle of the new model is presented based on the regional analysis of semiconductor device operation. The appendix gives the detail derivation of the semiconductor regional models. Section IV applies the approaches to the IGBT modeling. The main contribution is the analysis of the voltage drop across the electron and hole flow lines by identifying the contribution of each semiconductor regions. Section V corresponds to the simulation of the model in static condition and Section VI discusses about the comparison with experimental results on various IGBT part numbers. Section VII is a conclusion.

\section{State-of-the-art of IGBT modeling}

An IGBT is a semiconductor structure that combines the advantages of a MOSFET and a bipolar junction transistor. The structure of the elementary cell of an IGBT (Fig. 1) stems from that of a Vertical Double Diffused MOSFET (VDMOSFET). In a highly simplified way, it can be said that the $\mathrm{N}^{+}$drain substrate of the VDMOS structure is replaced by a $\mathrm{P}^{+}$collector substrate to form the IGBT structure. The design of an IGBT is multicellular, with parallel connections of all elementary cells, to reach a high current. In Fig. 1, four doping regions can 
be identified: The $\mathrm{N}^{+}$region at the top is the source of the MOSFET channel. The $\mathrm{P}^{+}$substrate at the bottom is the collector of the associated bipolar junction transistor (BJT). It is a holeinjecting layer. The $\mathrm{P} / \mathrm{P}+$ region is the channel of the MOSFET and the emitter of the BJT. Finally, the $\mathrm{N}^{-}$epitaxial layer, the N-base region, is the drain of the MOSFET channel and the bias to the gate of the IGBT structure creates an inversion layer channel under the gate electrode, in the P-region, which connects the $\mathrm{N}^{+}$source well to the N-base region. This allows the transport of electron current from the $\mathrm{N}+$ emitter region to the $\mathrm{N}$-base region when a positive voltage is applied to the collector terminal. Typical electron trajectory corresponds to the $\mathrm{E}^{\prime} \mathrm{C}^{\prime}$ cross-section in Fig. 1 . The holes are injected from the $\mathrm{p}^{+}$substrate. A typical hole trajectory corresponds to the EC cross-section in Fig. 1.

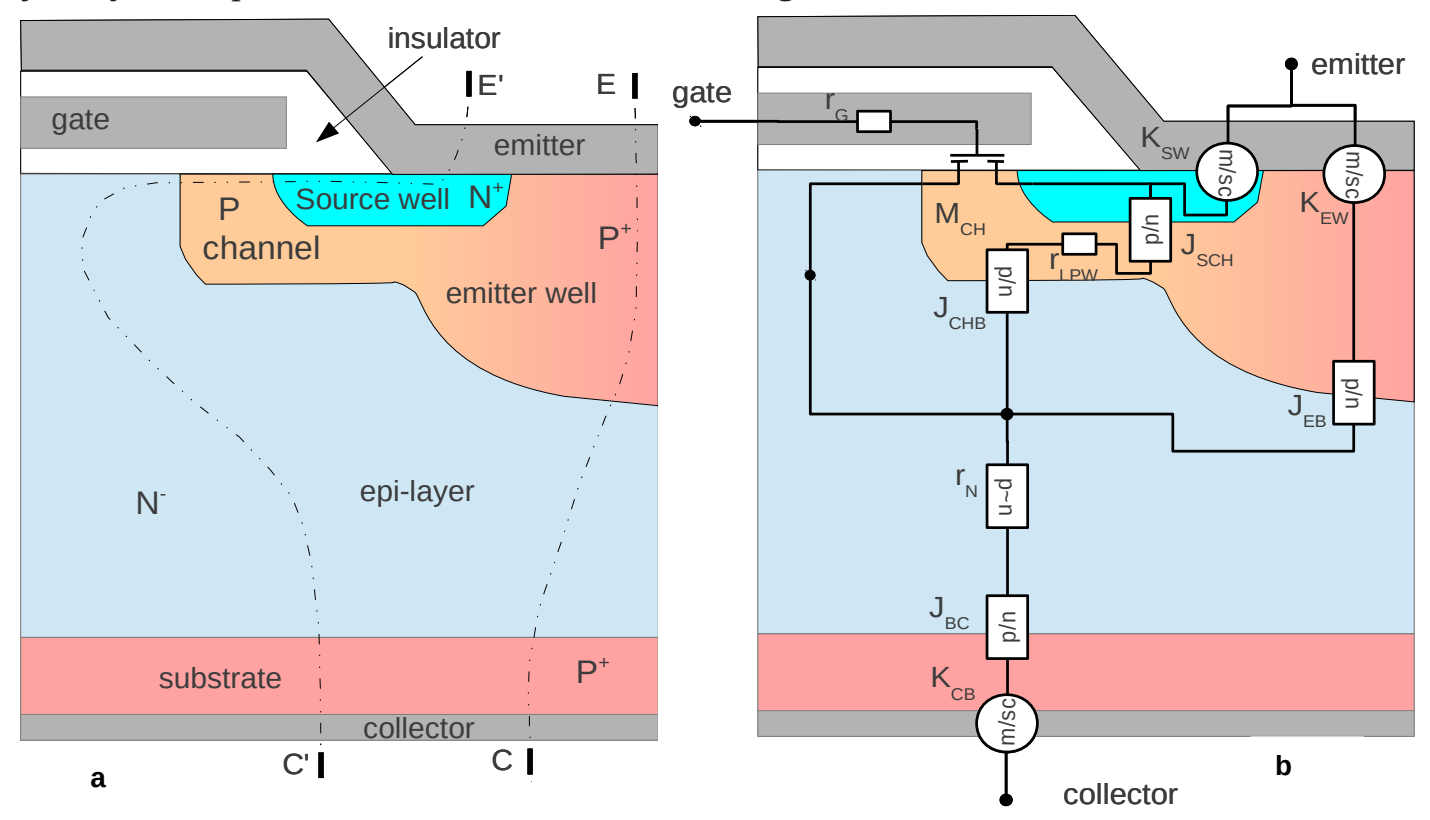

Fig. $1 \mathrm{a}$ ) Typical IGBT cell with contacts and the different doped regions and typical current flow lines for the electrons (E'C' cross-section) and the holes (EC cross-section). b) Superimposition of the IGBT structure and the proposed model. the circles represent sources, e.g. models that enforce a voltage. " $\mathrm{m} / \mathrm{sc}$ " is a metal semiconductor contact, Rectangles represent other elements like $\mathrm{p} / \mathrm{n}$ junctions " $\mathrm{p} / \mathrm{n}$ " or resistors. The complete list of symbols and their model equations is included in the appendix. Grey regions represents the IGBT contacts: emitter, gate and collector.

\section{Proposed Modeling Methodology}

In this section the modeling methodology is presented. The aim of the analysis is to improve the temperature dependency of the model by using regional dependencies. The modeling methodology is based on the well-known regional approach [2], which consists of spatial partitioning into neutral and space-charge regions by defining the boundaries (See Table 2). Moreover, the schematic cross-section of a typical planar IGBT in Fig. 1a allows the voltage drops along the electron and hole flow lines to be to analyze. This analysis may be applied to any semiconductor devices and yields to a systematic modeling approach. The analysis of trench IGBTs needs further development even if most of the consequences should be at high current levels and are of secondary effects. This analysis is quite different from the Hefner's famous model [1] because the analogy is not made at the electronic device level as a combination of diodes, MOSFETs, or BJTs with empirical temperature dependence. Instead, it is based on a combination of semiconductor regions, with local parameters and variables (Fig. 1b) and their 
associated physical-based temperature dependence. The regional approach is based on the observation of very different behaviors inside a semiconductor device, mainly depending on whether the region is neutral or not. The various regions required to model an IGBT are listed in Table 2. For the sake of simplicity, only local 1D approaches were addressed in the paper. The modeling of semiconductor regions fit well with the bond graph theory [6] , but the circuit representation is more widely accepted amongst electricians, so it was used in the paper. The appendix gives a short description of the semiconductor region models described in [6] . Note that it is limited to the models required to represent the proposed IGBT model.

\begin{tabular}{|c|c|c|c|c|}
\hline Symbol & Definition & Dependencies & Value & Units \\
\hline$q$ & Elementary charge & Physical constant & $1.602 \times 10^{-19}$ & C \\
\hline$k_{\mathrm{B}}$ & Boltzmann constant & Physical constant & $1.381 \times 10^{-23}$ & $\mathrm{~J} / \mathrm{K}$ \\
\hline $\mathrm{T}$ & Absolute temperature & $(\mathrm{t}, \mathrm{x})$ & Ta 300 & $\mathrm{~K}$ \\
\hline $\mathrm{u}_{\mathrm{T}}$ & Thermal potential & $(t, x)$ & $\mathrm{K}_{\mathrm{B}} \mathrm{T} / \mathrm{q}$ & V \\
\hline $\mathrm{n}$ & Electron concentration & $(t, x)$ & & $\mathrm{cm}^{-3}$ \\
\hline $\mathrm{p}$ & Hole concentration & $(t, x)$ & & $\mathrm{cm}^{-3}$ \\
\hline$n_{i}$ & Intrinsic concentration & $(\mathrm{T})$ & $1.45 \times 10^{10}$ & $\mathrm{~cm}^{-3}$ \\
\hline$\Gamma$ & Net Doping Concentration & $(\mathrm{x})$ & & $\mathrm{cm}^{-3}$ \\
\hline$\rho$ & Space Charge Density & $(\mathrm{t}, \mathrm{x})$ & & $\mathrm{C} / \mathrm{cm}^{3}$ \\
\hline$\mu_{\mathrm{n}}$ & Electron Mobility & $(\mathrm{T})$ & 1000 & $\mathrm{~cm}^{2} / \mathrm{V} / \mathrm{s}$ \\
\hline$\mu_{\mathrm{p}}$ & Hole Mobility & $(\mathrm{T})$ & 500 & $\mathrm{~cm}^{2} / \mathrm{V} / \mathrm{s}$ \\
\hline$\varepsilon_{\mathrm{SI}}$ & Dielectric constant of the silicon & Semiconductor constant & $1.05 \times 10^{-12}$ & $\mathrm{~F} / \mathrm{cm}$ \\
\hline
\end{tabular}

Table 1: Symbols and values.

\subsection{Neutral region modeling}

A neutral region is characterized by the absence of charge density given by the following condition: $|\rho| \ll q \max (p, n, \Gamma)$

So the charge density may be neglected: $\quad \rho=(p-n+\Gamma) \simeq 0$

Indeed, this is just an approximation and electron, hole and doping concentrations yield relative neutrality. However, different types of neutral regions exist. The high-level injection, HLI, occurs in bipolar devices like PIN diodes, BJTs, and IGBTs in forward conditions when the minority carrier concentration becomes higher than the doping concentration [5] because of the injection of minority carriers through the junction. In HLI, Equation (2) may be simplified as, $p \simeq n$ (3) In low-level injection, LLI, the minority carrier concentration is lower than the doping concentration, and the remaining issue concerns the diffusion of majority carriers, which only occurs in a LLI neutral region with a gradient of the doping concentration.

\subsection{Ohmic Contact Region with a Doping Gradient under LLI, OCDG.}

This is the case of any ohmic contact region. Because of the majority carrier diffusion due to the 
doping concentration gradient, an electric field producing a drift current compensates for the diffusion current. This electric field involves a constant voltage drop through the DGN region defined by (see the appendix (43)): $v_{B I}=-\chi u_{T} \ln \left(\frac{N_{B}}{n_{i}}\right)$

The temperature dependence of (4) comes from that of $n_{i}$, as defined (in the appendix) in (19).

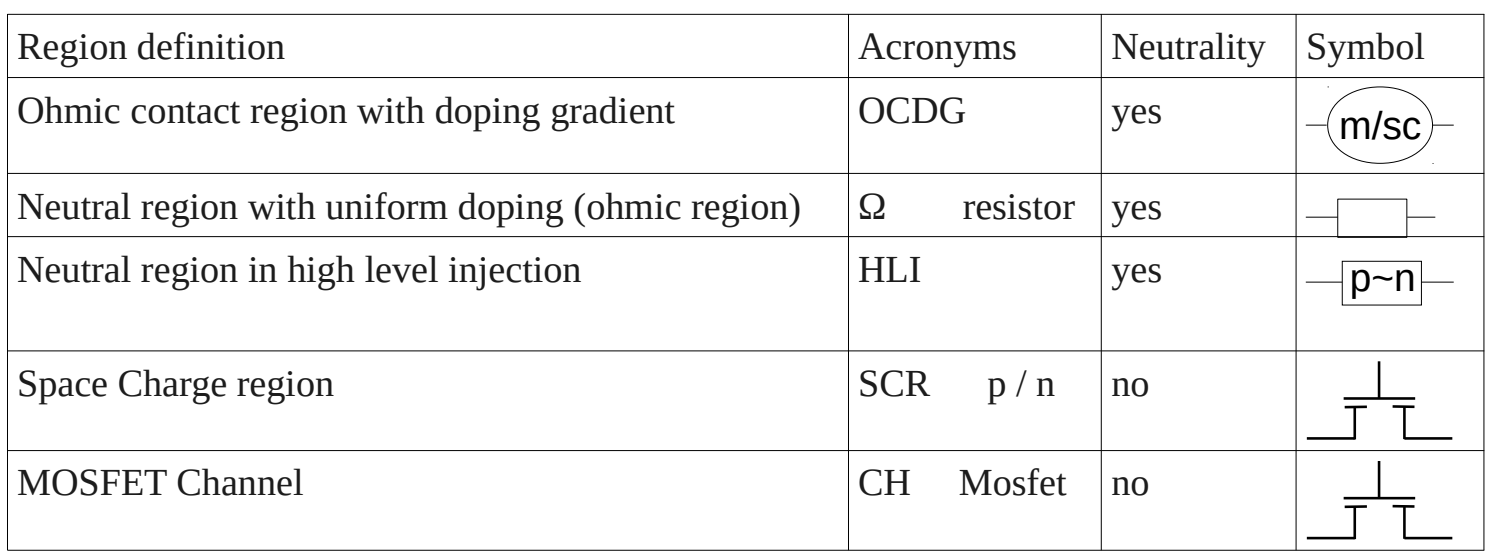

Table 2. Semiconductor regions used in the proposed IGBT model.

\subsection{Neutral region with uniform doping (ohmic region), $\Omega$}

When there is no gradient in the doping concentration, this is an ohmic region, i.e. a neutral region with a uniform doping concentration in LLI. An ohmic region is characterized by its resistance value, which in the case of an $\mathrm{N}$-type ohmic region is given by:

$$
r_{N}=\frac{W_{R}}{q \mu_{n} N_{D} A}
$$

\begin{tabular}{|l|l|l|l|}
\hline Symbol & Definition & Type & Unit \\
\hline $\mathrm{N}_{\mathrm{B}}$ & $\begin{array}{l}\text { Doping concentration at the boundary of } \\
\text { the neutral region }\end{array}$ & Region and device parameter & $\mathrm{cm}^{-3}$ \\
\hline $\mathrm{V}_{\mathrm{BI}}$ & $\begin{array}{l}\text { Drop voltage between the metallic contact } \\
\text { and the boundary of the neutral region }\end{array}$ & Region output variable (Voltage) & $\mathrm{V}$ \\
\hline $\mathrm{X}$ & $\begin{array}{l}\text { Type index } \\
1 \text { for a P-type, } \\
-1 \text { for a N-type }\end{array}$ & \\
\hline
\end{tabular}

Table 3: Symbols of the DGN region of type N. See the appendix (43).

\begin{tabular}{|l|l|l|l|}
\hline Symbol & Definition & Type & Unit \\
\hline $\mathrm{N}_{\mathrm{D}}$ & $\begin{array}{l}\text { Value of the uniform doping donor } \\
\text { concentration }\end{array}$ & Region and device parameter & $\mathrm{cm}^{-3}$ \\
\hline $\mathrm{A}$ & Device area & Region and device parameter & $\mathrm{cm}^{2}$ \\
\hline $\mathrm{W}_{\mathrm{R}}$ & Ohmic region width & Region variable & $\mathrm{cm}$ \\
\hline $\mathrm{r}_{\mathrm{N}}$ & Resistance value & Region variable & $\Omega$ \\
\hline
\end{tabular}

Table 4: Symbols of the N-type ohmic region.

\subsection{Neutral region in HLI}

As shown in the appendix, in case of HLI, the voltage drop is classically given by (51), i.e. 


$$
v_{N}=R_{D} i_{p n}+v_{D}
$$

Particularly, using a linear approximation of the plasma in the HLI region as proposed by Hefner [8] , the approximations of $R_{D}$ and $V_{D}$ are given by (67) and (69), respectively. The value of $R_{D}$ is related to the LLI value $r_{N}$ defined in (5).

\begin{tabular}{|l|l|l|l|}
\hline Symbol & Definition & Type & Unit \\
\hline $\mathrm{i}_{\mathrm{pn}}$ & Current flowing through the high level injection region & Region variable & $\mathrm{A}$ \\
\hline $\mathrm{V}_{\mathrm{N}}$ & Voltage drop through the high level injection region & Region variable & $\mathrm{V}$ \\
\hline $\mathrm{R}_{\mathrm{D}}$ & Dynamic resistance of the high level injection region & Region variable & $\Omega$ \\
\hline $\mathrm{V}_{\mathrm{D}}$ & Dynamic voltage drop of the high level injection region & Region variable & $\mathrm{V}$ \\
\hline
\end{tabular}

Table 5: Symbols for the HLI region.

\subsection{Space Charge Region}

The modeling of the space charge region (SCR) is very classic with the assumption of an abrupt asymmetric junction [5] : see the appendix and equations (70), (78), (80), and (81).

\subsection{Mosfet Channel, MCH}

The model is based on the MOSFET channel model introduced by Hefner et al. [1] which uses two transconductances $K_{p}^{\text {lin }}$ and $K_{p}^{\text {sat }}$ to better represent the current in the channel. $K_{p}^{\text {lin }}$ corresponds to the linear region and $K_{p}^{\text {sat }}$ corresponds to the saturation region of the static characteristics $I_{D}\left(V_{D S}\right)$. See the appendix and equations(82-84). In this section the modeling methodology has been presented. The semiconductor region models are derived from the same methodology in the appendix.

\section{IGBT MODELING}

In this section the model of the IGBT is derived using the semiconductor region models presented in section 3. The regional approach is then applied to a standard IGBT cell as shown in Fig.1a. The proposed model consists essentially of four parts: the MOSFET model, the neutral zone with doping gradient (diffusion) $\mathrm{V}_{\mathrm{Bi}}$, the barrier height of the area of the space charge Uв and the plasma. According to the cross-sections E'-C' and E-C the resulting model presents the topology of the model developed directly on the physical structure. Fig. 1 shows a typical IGBT cell with the superimposed model that includes 9 semiconductor region models plus two resistors. The choice of the semiconductor model type is straightforward because of the presence of doping regions, which form junctions. In practice, two paths are considered: the flow lines of the electrons and those of the holes in cross-section $\mathrm{E}^{\prime} \mathrm{C}^{\prime}$ and in cross-section EC respectively as shown in Fig. 1. The analysis of the drops voltage along the trajectories of electrons and that of holes enable to identify the nature of semiconductor regions to be used Fig. 2.

\subsection{Analysis of the voltage drops along the electron flow line $E^{\prime}-C^{\prime}$}

Fig. 2 shows the typical doping profile and the associated electric potential along the $\mathrm{E}^{\prime} \mathrm{C}$ '

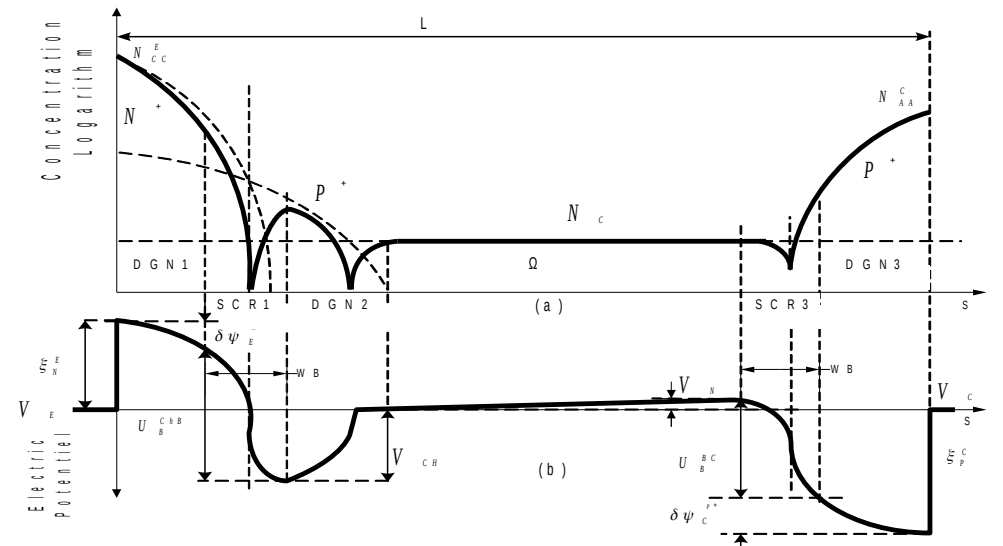

Fig. 2: Typical doping profile and electric potential along the electrons flow lines $E^{\prime} C$ '. 
cross-section view. The drops in the voltage along this flow line yields

$$
v_{C E}=V_{B I}^{E W}+u_{B}^{E B}+v_{N}-u_{B}^{B C}-V_{B I}^{C B}
$$

\begin{tabular}{|l|l|l|}
\hline Symbol & Definition & Unit \\
\hline$i_{C}$ & Current flowing through the collector & $\mathrm{A}$ \\
\hline$i_{C H}$ & Current flowing through the channel & $\mathrm{A}$ \\
\hline$i_{G}$ & Current flowing through the gate & $\mathrm{A}$ \\
\hline$v_{N}$ & Voltage drop through the high level injection region & $\mathrm{V}$ \\
\hline$v_{C H}$ & Channel potential & $\mathrm{V}$ \\
\hline$u_{B}^{E B}$ & Junction Emitter-Base barrier potential & $\mathrm{V}$ \\
\hline$u_{B}^{C H B}$ & Channel-Base barrier potential & $\mathrm{V}$ \\
\hline$u_{B}^{B C}$ & Collector base barrier potential & $\mathrm{V}$ \\
\hline$u_{B}^{S C H}$ & Source-Chanel barrier potential & $\mathrm{V}$ \\
\hline$v_{B I}^{S W}$ & Source well contact to Space Charge Region building potential & $\mathrm{V}$ \\
\hline$v_{B I}^{E W}$ & Emitter well contact to Space Charge Region building potential & $\mathrm{V}$ \\
\hline$v_{B I}^{C B}$ & Collector base contact to Space Charge Region building potential & $\mathrm{V}$ \\
\hline
\end{tabular}

Table 6: Variables of the proposed IGBT model.

\subsection{Analysis of the voltage drops along the hole flow lines EC}

Fig. 3 presents the typical doping concentration and electric potential along the EC crosssection view which is split into neutral and space charge regions. The analysis of the drops in the voltage (Fig. 1, Fig. 3, and Fig. 4) yields $v_{C E}=V_{B I}^{S W}+v_{C H}+v_{N}-u_{B}^{B C}-V_{B I}^{C B}$

So the combination of Equations (7) and (8) yields to $V_{B I}^{E W}+u_{B}^{E B}=V_{B I}^{S W}+v_{C H}$

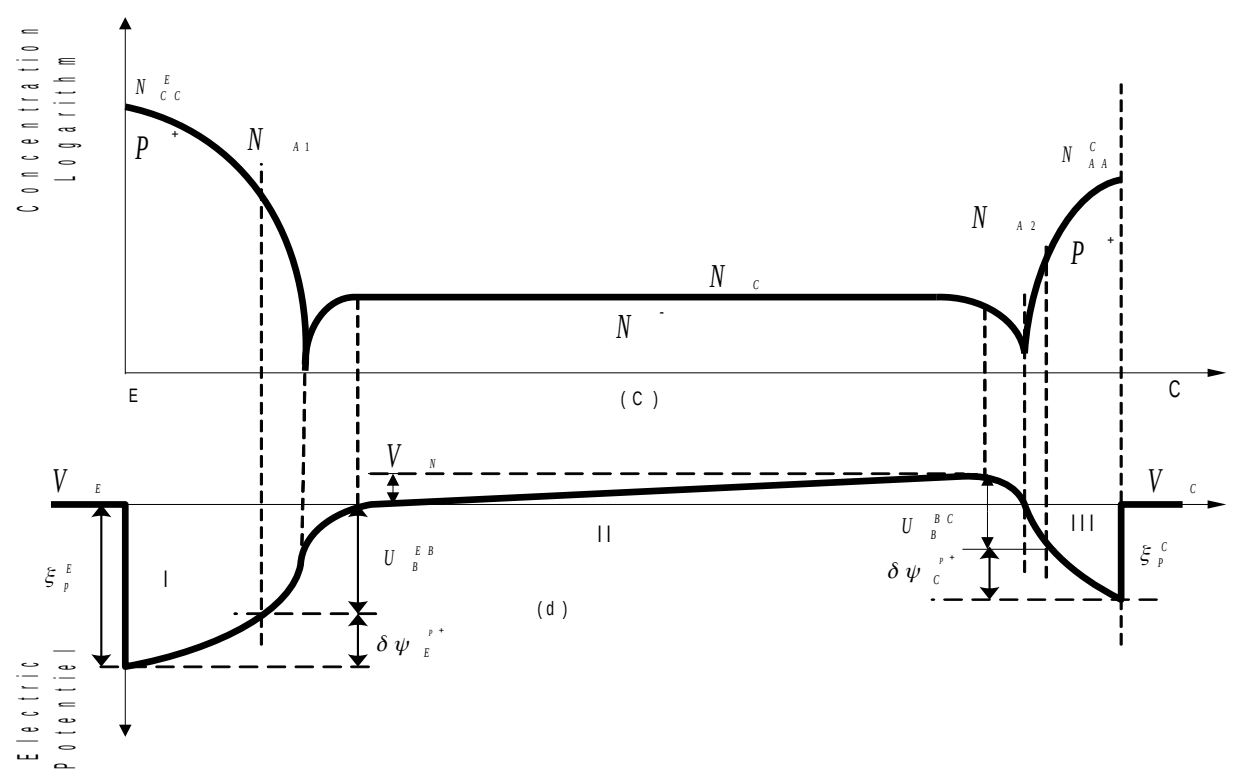

Fig. 3: Typical doping profile and electric potential along the holes flow lines EC . 


\begin{tabular}{|l|l|l|l|}
\hline Identifier & Definition & Type & Corresponding Voltage/Current \\
\hline $\mathrm{K}_{\mathrm{EW}}$ & Emitter well contact region & OCDG & $v_{B I}^{E W}$ \\
\hline $\mathrm{J}_{\mathrm{EB}}$ & Emitter-Base junction region & $\mathrm{SCR}$ & $u_{B}^{E B}$ \\
\hline $\mathrm{r}_{\mathrm{N}}$ & Ohmic and plasma region & HLI & $v_{N}, i_{C}$ \\
\hline $\mathrm{J}_{\mathrm{BC}}$ & Base-Collector junction region & $\mathrm{SCR}$ & $u_{B}^{B C}$ \\
\hline $\mathrm{K}_{\mathrm{CB}}$ & Collector-Base contact region & OCDG & $v_{B I}^{C B}$ \\
\hline $\mathrm{K}_{\mathrm{SW}}$ & Source-Chanel contact region & OCDG & $v_{B I}^{S W}$ \\
\hline $\mathrm{M}_{\mathrm{CH}}$ & MOSFET channel region & $\mathrm{CH}$ & $v_{C H}, i_{C H}$ \\
\hline $\mathrm{J}_{\mathrm{CHB}}$ & Channel-Base junction region & $\mathrm{SCR}$ & $u_{B}^{C H B}$ \\
\hline $\mathrm{J}_{\mathrm{SCH}}$ & Source-Channel junction region & $\mathrm{SCR}$ & $u_{B}^{S C H}$ \\
\hline $\mathrm{r}_{\mathrm{G}}$ & Gate access resistor & $\mathrm{R}$ & $i_{G}$ \\
\hline $\mathrm{r}_{\mathrm{LPW}}$ & Lateral resistor of the P-well & $\mathrm{R}$ & \\
\hline
\end{tabular}

Table 7: List of the semiconductor region components used in the proposed IGBT model.

The application of the region analysis yields the model illustrated in Fig. 4 that uses the semiconductor region models defined in the appendix. For instance, the presented model is very different from Hefner model in the use of the building potential which is distributed in our model in 3 different elements KEW, KCB and KSW representing the 3 semiconductor-metal contacts with 3 different currents. The following section applies the model to the simulation of the IGBT. For each path in Fig. 4, the pn junctions (SCR elements) are first placed. Then, depending on the region behavior, a neutral element is added to complete the path. A third path, which includes $\mathrm{J}_{\mathrm{SCH}}$ and $\mathrm{J}_{\mathrm{CHB}}$ is added to ensure the convergence in off-state. However, such junctions exist.

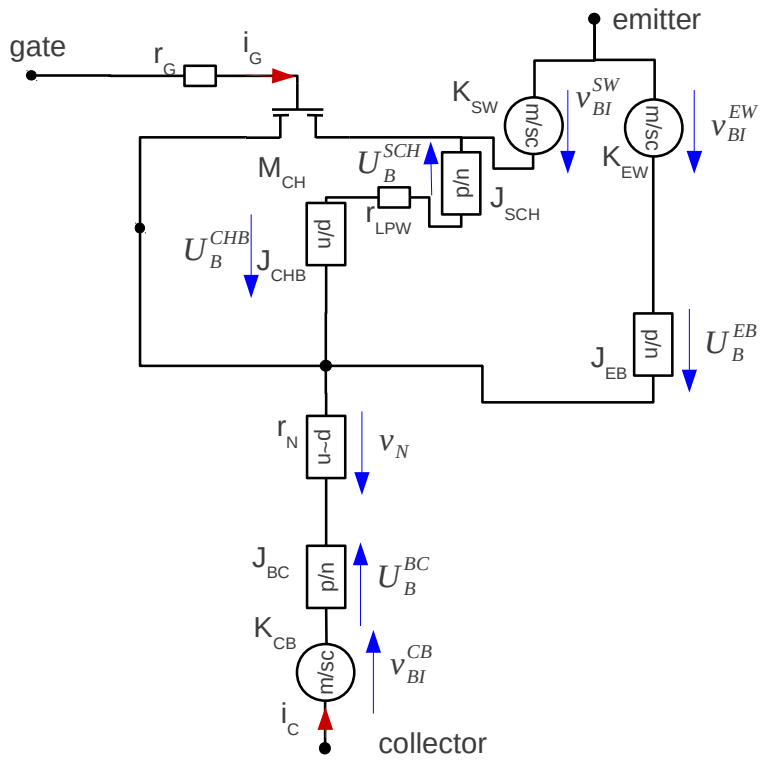

Fig. 4: Proposed model as given in Fig. $1 b$ 


\section{Simulation of the IGBT model}

For a good accuracy of the model, it is necessary to be able to correctly define the parameters of the model. The models (Models OCDG, HLI, SCR, and CH in Table 7 ) in Fig. 4 are implemented as elementary MAST models in SABER. The implementation is also possible with other platforms such as those based on VHDL-AMS.

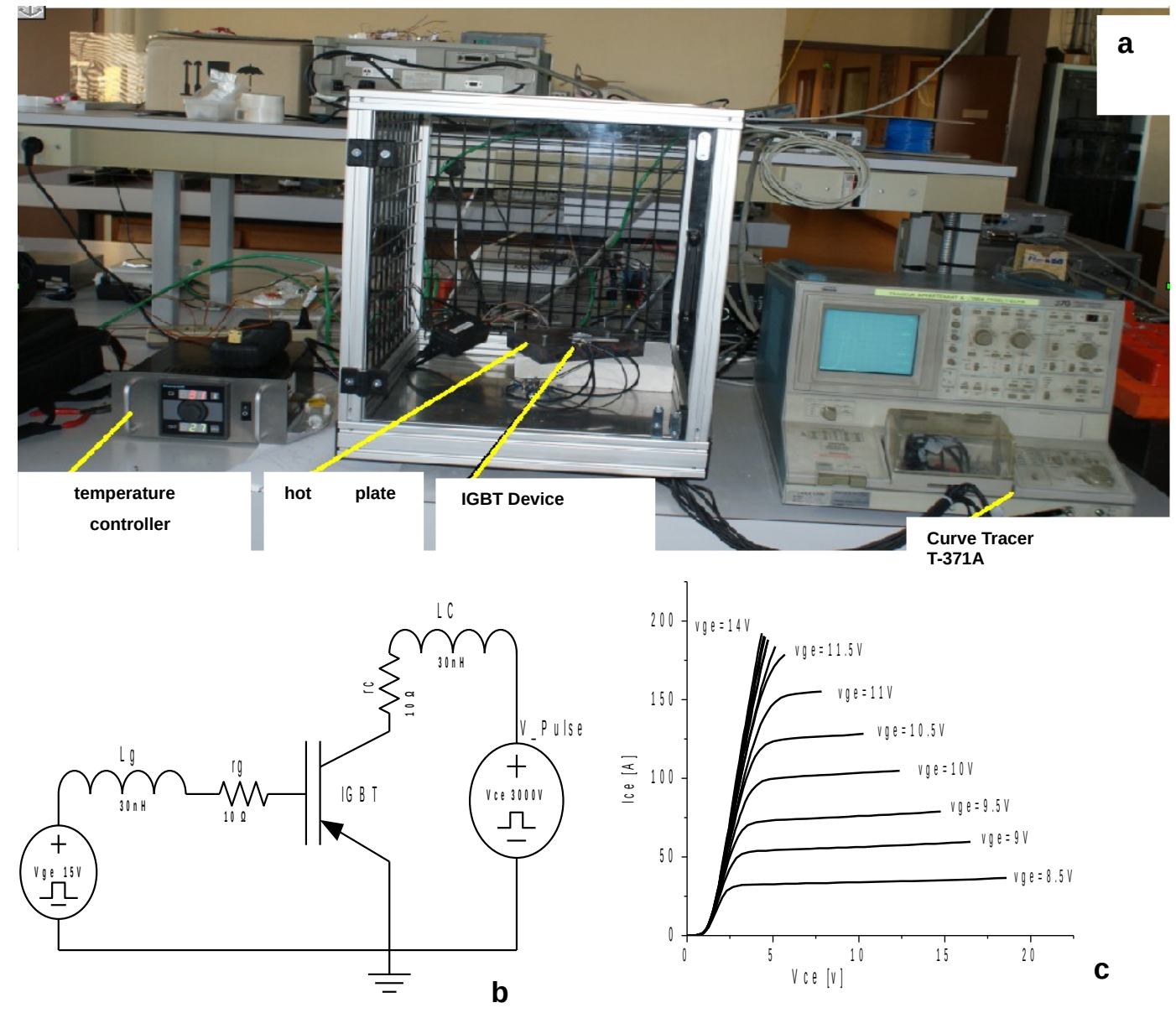

Fig. 5: a) Test bench for the measurement of the static characteristics of the IGBT at various temperatures, b) IGBT simulation circuit, c) Simulated static characteristics of the IGBT IRG4PC50U.

Fig. 5 presents the test bench used to measure the static characteristics of the IGBT at various temperatures. Tektronix 370 and $371 \mathrm{~A}$ curve tracers were used to measure the static characteristics in pulsed mode with a low-duty cycle to limit the influence of the self-heating of the IGBT during the measurements. To perform the measurements, the following different components are used : IRG4PC50S (Standard Speed IGBT), IRG4BC40F (Fast Speed IGBT), IRG4PC30U (Ultra Fast Speed IGBT), GT50J325, GT20J321 (High power and Fast Switching Application). To study the influence of the temperature, the device under test, DUT, is placed on a temperature-controlled hot plate associated with a protection cage. The temperature is measured with a thermocouple as shown in Fig. 5. Fig. 5c shows a typical static characteristics obtained with the proposed model. Fig. 5b shows the simulation circuit used to test the model in transient conditions. The experimental characteristics obtained for these different components are compared with the simulated characteristics of the new model and that of the Hafner model in order to extract parameters. The obtained results are presented for a single component in Fig 6. Those of the other components are presented in Table 8. 

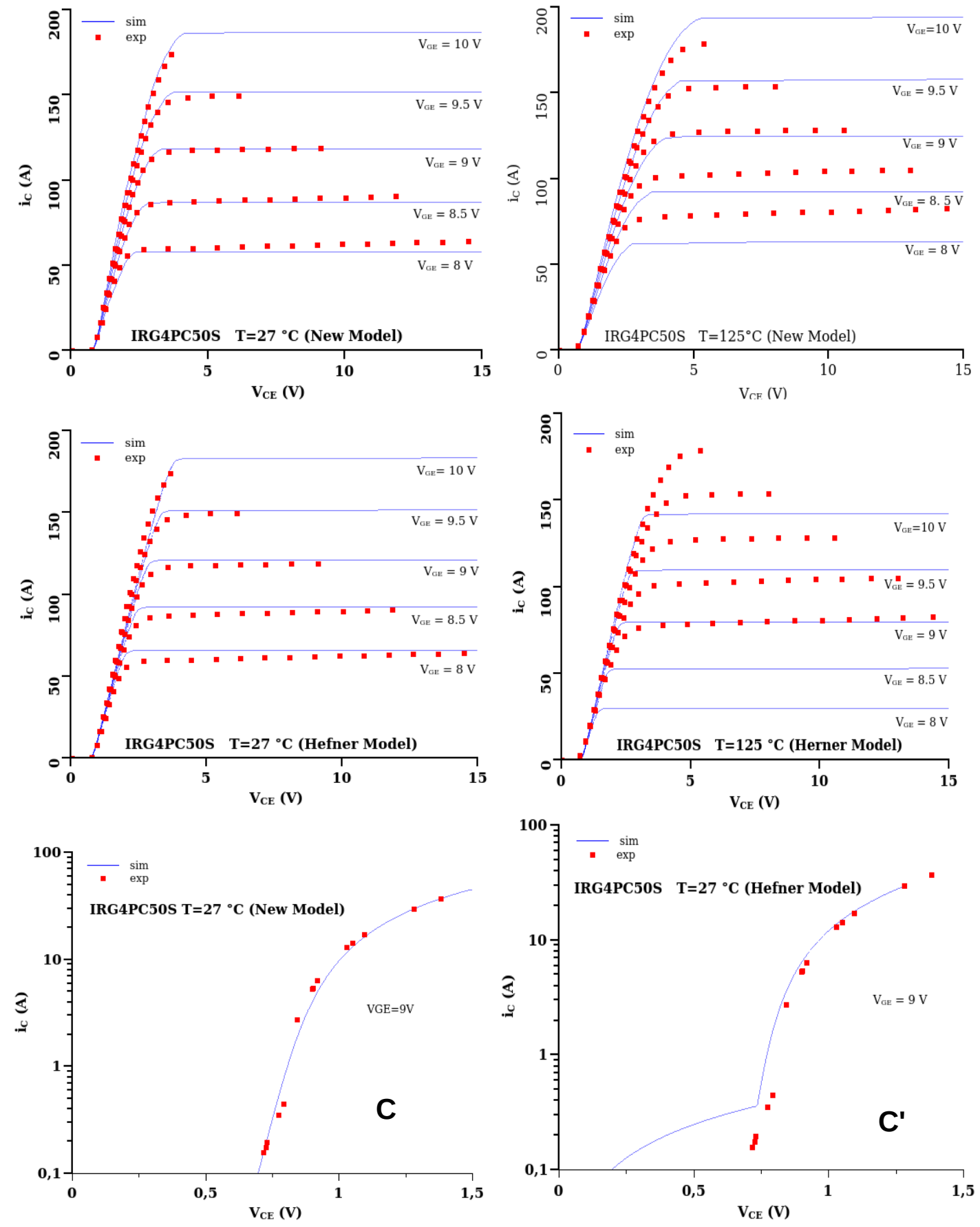

Fig. 6 : Measured and simulated static characteristics for the new model and the Hefner model at $27^{\circ} \mathrm{C}$, and $125^{\circ} \mathrm{C}$, respectively. The bottom graphs present the low-level current versus the applied voltage for both models, at a gate-to-source voltage of $9 \mathrm{~V}$, highlighting the accuracy of the models at low currents.

\section{Discussion}

While the IGBT is on, the collector-emitter voltage $\left(\mathrm{V}_{\mathrm{CE}}\right)$ changes in accordance with the collector current $\left(\mathrm{I}_{\mathrm{C}}\right)$, gate voltage $\left(\mathrm{V}_{\mathrm{GE}}\right)$, and temperature $(\mathrm{T})$. The $\mathrm{V}_{\mathrm{CE}}$ represents a collectoremitter voltage drop in the ON state. The dependence of $\mathrm{V}_{\mathrm{CE}}-\mathrm{V}_{\mathrm{GE}}$ on $\mathrm{I}_{\mathrm{C}}$ is shown on the graph in Fig. $6\left(\mathrm{~T}=25^{\circ} \mathrm{C}\right)$, and $\left(\mathrm{T}=125^{\circ} \mathrm{C}\right) . \mathrm{V}_{\mathrm{CE}}$ increases in direct proportion to the collector current and inversely proportional to the $\mathrm{V}_{\mathrm{GE}}$ value. The parameter extraction process at the different 
temperatures ([1] , [11] , [12] ) was based on the minimization of the error between simulations and measurements of the static characteristics for both the Hefner model and the new established model. The parameters that describe the MOSFET channel have a weak influence on the static characteristics, whereas other parameters, such as $N_{D}$ and $W_{B}$ have a very weak influence. Therefore, they were set using the breakdown voltage of the transistor, as proposed in [11] . The ambipolar lifetime was set to $100 \mathrm{~ns}$. Its influence is further important at the turn-off transient.

\begin{tabular}{|c|c|c|c|c|c|c|c|c|c|c|c|c|c|c|c|}
\hline \multirow{4}{*}{ 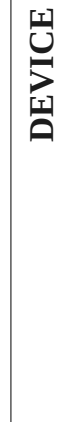 } & \multirow{4}{*}{ 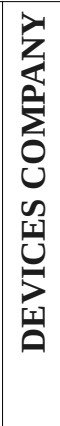 } & 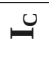 & \multirow{4}{*}{$\stackrel{\bar{g}}{\tilde{g}}$} & \multirow[t]{4}{*}{$3^{\infty}$} & \multirow{4}{*}{$\begin{array}{l}z^{\infty} \\
\text { ? } \\
\text { g }\end{array}$} & \multirow{4}{*}{$\begin{array}{l}5 \\
>\end{array}$} & \multirow{4}{*}{$\begin{array}{l}0 \\
\overrightarrow{1} \\
\vec{b}\end{array}$} & \multirow{4}{*}{$\frac{k_{p}^{\operatorname{lin}}}{k_{p}^{\text {sot }}}$} & $k^{\text {sot }}$ & \multicolumn{6}{|c|}{ Relative Error: $\Delta \mathrm{I} / \mathrm{I}(\%)$} \\
\hline & & \multirow[t]{3}{*}{$\varangle$} & & & & & & & $\stackrel{2}{2}$ & \multicolumn{4}{|c|}{ Saturation region } & \multirow{2}{*}{\multicolumn{2}{|c|}{$\begin{array}{l}\text { Ohmic } \\
\text { region } \\
V_{\mathrm{GE}}>9.5 \mathrm{~V}\end{array}$}} \\
\hline & & & & & & & & & & \multicolumn{2}{|c|}{$\mathrm{V}_{\mathrm{GE}}=9.5 \mathrm{v}$} & \multicolumn{2}{|c|}{$\mathrm{V}_{\mathrm{GE}}=9 \mathrm{v}$} & & \\
\hline & & & & & & & & & & 岺 & $\begin{array}{l}\stackrel{u}{\stackrel{\circ}{0}} \\
\stackrel{\sim}{v}\end{array}$ & $\begin{array}{l}\text { U. } \\
\stackrel{\circ}{N}\end{array}$ & $\begin{array}{l}\stackrel{u}{\stackrel{\nu}{n}} \\
\stackrel{\sim}{v}\end{array}$ & $\begin{array}{l}\text { U } \\
\stackrel{\circ}{N}\end{array}$ & $\begin{array}{l}\stackrel{\circ}{\stackrel{\nu}{n}} \\
\text { In }\end{array}$ \\
\hline \multirow{2}{*}{ 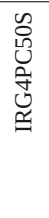 } & \multirow{2}{*}{ 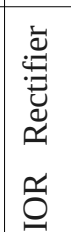 } & \multirow[t]{2}{*}{$\vec{\forall}$} & 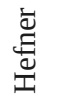 & $\curvearrowright$ & $\begin{array}{l} \pm \\
\stackrel{ \pm}{0} \\
\stackrel{1}{m}\end{array}$ & के & $\begin{array}{l}\text { ల్ } \\
\text { లై }\end{array}$ & $\nabla$ & $\stackrel{\varphi}{n}$ & $\stackrel{\infty}{\infty}$ & $\begin{array}{l}0 \\
\stackrel{\sim}{\sim}\end{array}$ & $\stackrel{\sim}{\sim}$ & $\stackrel{\llcorner ?}{\widehat{n}}$ & हे & $\stackrel{\bullet}{\circ}$ \\
\hline & & & $\stackrel{3}{=}$ & i & $\underset{\sim}{ \pm}$ & बु & $\begin{array}{l}\text { ले } \\
\text { लె. }\end{array}$ & $\underset{-}{\sim}$ & $\ddot{\theta}$ & $\stackrel{\text { Lִ }}{0}$ & $\stackrel{\varphi}{\sim}$ & $\stackrel{-}{\circ}$ & $\vec{\lambda}$ & $\stackrel{-}{-}$ & $\stackrel{m}{i}$ \\
\hline \multirow[t]{2}{*}{ 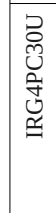 } & \multirow{4}{*}{ 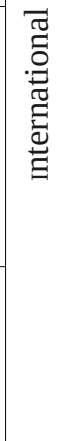 } & \multirow[t]{2}{*}{$\underset{\nearrow}{ユ}$} & 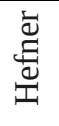 & $\stackrel{\sim}{N}$ & 웅 & 7 & กั & $\stackrel{2}{\longrightarrow}$ & i & $\hat{o}$ & $\stackrel{\llcorner ?}{\stackrel{n}{m}}$ & $\stackrel{\infty}{0}$ & $\hat{\text { ⿵े }}$ & 2,2 & $\underset{\sim}{\sim}$ \\
\hline & & & 总 & $\stackrel{\llcorner}{\sim}$ & 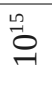 & $\begin{array}{l}\circ \\
0\end{array}$ & $\stackrel{m}{0}$ & $\vec{\infty}$ & $\stackrel{\infty}{\dot{J}}$ & $\stackrel{+}{\circ}$ & $\stackrel{\varphi}{0}$ & $\stackrel{\infty}{\rightarrow}$ & $\hat{\nu}$ & -1 & $\stackrel{\varphi}{-}$ \\
\hline \multirow{2}{*}{ 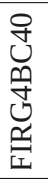 } & & \multirow[t]{2}{*}{$\hat{~}$} & 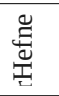 & $\stackrel{\llcorner}{N}$ & $\stackrel{2}{2}$ & ถึ & 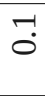 & $m$ & $\ddot{N}$ & $\ddot{0}$ & $\underset{\text { ㄱ }}{\mathcal{\gamma}}$ & $\stackrel{\infty}{\infty}$ & $\stackrel{\sim}{\forall}$ & $\vec{\infty}$ & $\stackrel{m}{0}$ \\
\hline & & & 3 & $\stackrel{\llcorner}{N}$ & $\stackrel{0}{\circ}$ & $\stackrel{\nabla}{\bullet}$ & $\stackrel{t}{0}$ & $\begin{array}{l}\infty \\
\text { ọ } \\
0\end{array}$ & $\begin{array}{l}\text { Ln } \\
\text { Ln } \\
\text { ñ }\end{array}$ & $\ddot{0}$ & $\hat{\circ}$ & $\stackrel{-1}{1}$ & $\stackrel{20}{0}$ & $\stackrel{m}{-1}$ & $\stackrel{+}{+}$ \\
\hline \multirow[t]{2}{*}{ 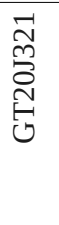 } & \multirow{4}{*}{ 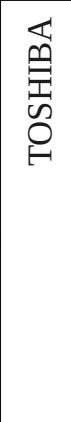 } & \multirow[t]{2}{*}{ 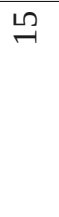 } & 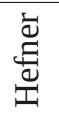 & $\stackrel{\llcorner}{N}$ & $\stackrel{2}{\circ}$ & $\begin{array}{ll}\infty & 0 \\
0 & 0\end{array}$ & กั & $\stackrel{m}{\rightarrow}$ & A & $\ddot{0}$ & $\begin{array}{l}\text { Oे } \\
\dot{m}\end{array}$ & $\stackrel{\circ}{i}$ & חִ & $\overrightarrow{\dot{H}}$ & $\stackrel{2}{\sim}$ \\
\hline & & & 总 & $\stackrel{\llcorner}{\sim}$ & 울 & $\stackrel{\nabla}{6}$ & กั & बे & $\begin{array}{l}0 \\
\infty\end{array}$ & $\stackrel{n}{\pi}$ & बे & $\stackrel{\curvearrowright}{-}$ & $\overrightarrow{0}$ & $\begin{array}{l}\dot{\varphi} \\
\dot{\theta}\end{array}$ & $\stackrel{m}{\sim}$ \\
\hline \multirow{2}{*}{ 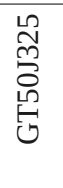 } & & \multirow[t]{2}{*}{ ㅇํ } & $\begin{array}{l}\overline{\mathbb{U}} \\
\text { 离 }\end{array}$ & $\stackrel{\llcorner}{\sim}$ & 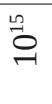 & $\stackrel{\nabla}{\emptyset}$ & ت. & $m$ & ฉ & $\stackrel{\infty}{\infty}$ & $\begin{array}{l}\infty \\
\ddot{\theta}\end{array}$ & $\stackrel{\circ}{\circ}$ & $\overline{6}$ & $\Lambda$ & $\stackrel{\bullet}{\square}$ \\
\hline & & & 总 & $\stackrel{\llcorner}{N}$ & 뭉 & t. & -1 & 냉 & $\vec{d}$ & -7 & m. & $\begin{array}{l}\text { oे } \\
\text { ¿े }\end{array}$ & $\begin{array}{l}\infty \\
\dot{0} \\
\dot{0}\end{array}$ & 0 & $\stackrel{9}{=}$ \\
\hline
\end{tabular}

Table 8: Parameters of both Hefner and the proposed models identified for the various component references tested and the corresponding error between measurement and simulation (the maximal error in saturation mode). All devices have $V_{C E}^{\max }=600 \mathrm{~V}$. The current ratings are given in column $I_{C}$.

Fig. 6 shows the comparison between measurements and simulations for the Hefner model and the new model at $27^{\circ} \mathrm{C}$ and $125^{\circ} \mathrm{C}$ for the IRG4PC50S transistor. 8 shows the parameters used for the simulations and the corresponding relative experiment. As the temperature increases, 
the relative error between the experiment and the simulation in saturation and linear mode for a voltage $\mathrm{V}_{\mathrm{GE}}<10 \mathrm{~V}$, is lower than $9 \%$ for the new model, and up to $77 \%$ for the Hefner model indicating that only the new model remains accurate at $\mathrm{T}=125{ }^{\circ} \mathrm{C}$ which proves that the new model is more precise than the Hefner model. Fig. 6 (c, c ') shows the behavior of both models at low current levels. The Hefner model shows some inaccuracies at a low current level, with little impact on global behavior. It is believed that the proposed model results in better temperature dependence because of the regional approach, which is based on the use of the local and physical temperature relations for parameters such as $\mathrm{V}_{\mathrm{BI}}, \mu_{\mathrm{n}}$ and $\mu_{\mathrm{p}}$.

\begin{tabular}{|l|l|l|l|}
\hline Symbol & Definition & Region Component & Unit \\
\hline $\mathrm{W}_{\mathrm{B}}$ & Base width, i.e. thickness of the epitaxial layer & $\mathrm{r}_{\mathrm{N}}$ & $\mathrm{cm}$ \\
\hline $\mathrm{N}_{\mathrm{B}}$ & Doping concentration in the epitaxial layer & $\mathrm{r}_{\mathrm{N}}$ & $\mathrm{cm}^{-3}$ \\
\hline$\tau$ & Ambipolar lifetime int the epitaxial layer & $\mathrm{r}_{\mathrm{N}}$ & $\mu \mathrm{S}$ \\
\hline $\mathrm{V}_{\mathrm{T}}$ & Threshold voltage & $\mathrm{M}_{\mathrm{CH}}$ & $\mathrm{V}$ \\
\hline$\theta$ & Mobility modulation factor & $\mathrm{M}_{\mathrm{CH}}$ & $\mathrm{V}^{-1}$ \\
\hline$K_{P}^{\text {lin }}$ & Transconductance in linear mode & $\mathrm{M}_{\mathrm{CH}}$ & $\mathrm{AV}^{-2}$ \\
\hline$K_{P}^{\text {sat }}$ & Transconductance in saturation mode & $\mathrm{M}_{\mathrm{CH}}$ & $\mathrm{AV}^{-2}$ \\
\hline
\end{tabular}

Table 9: Main parameters of the proposed IGBT model.

\section{Conclusion}

The originality of the present work lies in the development of a new analytical model based on regional analysis of IGBT semiconductor devices which describes in a better way its electrical and thermal behavior. This work involves the use of local and physical relations with accurate temperature dependencies. The accuracy of the proposed model is clearly higher than the standard Hefner model. However, the new model is only valid for static operation. The same principle of the regional approach may be applied to the derivation of a complete IGBT model: junction capacitors should be added. The main issue will be the HLI phenomenon, which is clearly explained in the Hefner paper [1] and enables the slowly decaying portion of the turn-off anode current to be represented which mainly depends on the ambipolar lifetime. The linear approximation of the Hefner model may be used to derive such a complete model, using a consistent HLI model for transient operation to replace the $r_{N}$ component in the presented model. However, further research is necessary to develop accurate models for new technologies such as trench, punch-through, and field stop.

\section{REFERENCES}

[1] Hefner, A.R., Jr.; Diebolt, D.M.; "An experimentally verified IGBT model implemented in the Saber circuit simulator", IEEE Transactions on Power Electronics, Volume: 9 Issue:5, Sep 1994, On page(s): 532 - 542

[2] Arora, N.D.; Rios, R.; Cheng-Liang Huang; Raol, K. ; « PCIM: a physically based continuous short-channel IGFET model for circuit simulation » IEEE Transactions on Electron Devices, Volume: 41 Issue:6, Jun 1994, On page(s): 988 - 997

[3] H. Morel, S.H. Gamal and J.P. Chante. - State Variable Modeling Of The Power PIN Diode Using An Explicit Approximation Of Semiconductor Device Equations: A Novel Approach IEEE Transaction on Power Electronics, Vol. 9, No. 1, January 1994, pp. 112-120

[4] SABER user guide, Synopsys, 2004.

[5] S.M. Sze, Kwok K. Ng, Physics of Semiconductor Devices, Willey Intersciences, 2007 
[6] H. Morel, "Modeling and simulation of power semiconductor devices and power electronic systems”, HdR disertation, 1994, INSA Lyon, France, http://tel.archives-ouvertes.fr/tel-00731059

[7] S. Selberherr, “Analysis and simulation of semiconductor devices”, Springer Verlag 1984.

[8] A. R. Hefner, Jr., and D. L.Blackburn, An Analytical Model for the Steady State And Transient Characteristics of The Power Insulated-Gate Bipolar Transistor, Solid State Electronics Vol 31. No 10 pp 1513-1532. 1988 Printed in Great Britain

[9] C. Snowden Introduction to Semiconductor Device Modelling. Copyright 1986 by Word scientifique Publishing Co. Pte. Ltd.

[10] Allen R. Hefner, Jr. " An Investigation of the Drive Circuit Requirements for the Power Insulated Gate Bipolar Transistor (IGBT)” IEEE Transactions on Power Electronics, VOL. 6. NO. 2. APRIL 1991

[11] Hatem Garrab, B. Allard, H. Morel, kaiçar Ammous, Sami Ghedira, Adel Amimi, Kamel Besbes, Jean-Michel Guichon, « On the Extraction Procedure of PIN diode Design Parameters for validation of Integrated Power Converter Design ", special issue on integrated power electronics, IEEE Trans. On Power Electronics, Vol. 20, No. 3, pp. 660-670. 2005.

[12] L. Hernandez, A. Claudio, M. A Rodriguez. M. Ponce and A. Topia, Physical Modeling of SiC Power Diodes with Empirical Approximation, Journal of power Electronics Vol. 11, No 3, May 2011

[13] W. Bludau, A. Onton, and W. Heinke, “Temperature dependence of the band gap in silicon,” Journal of Applied Physics, vol. 45, no.4, pp. 1846-1848, 1974.

[14] C. Lombardi et al., "A Physically Based Mobility Model for Numerical Simulation of Nonplanar Devices,” IEEE Transactions on Computer-Aided Design, vol. 7, no. 11, pp. 11641171, 1988.

\section{Appendix}

\section{A-One-dimensional Regional Approach Hypothesis}

The analysis is based on the classical semiconductor device equations (10-18) [6] [7] .

-Poisson's Equation $\frac{\partial \mathrm{E}}{\partial \mathrm{x}}=\frac{\rho}{\epsilon} \quad$ (10) $\quad E=-\frac{\partial \psi}{\partial x}$

where the space charge is defined by $\rho=q(\Gamma+p-n)$

Conservation Equations $q \frac{\partial p}{\partial t}+\frac{\partial J_{p}}{\partial t}=-q U \quad$ (13) $\quad-q \frac{\partial n}{\partial t}+\frac{\partial \vec{J}_{n}}{\partial x}=q U$

The total current density, J, is defined by $\quad J=J_{n}+J_{p}$

-Drift-Diffusion Equations $J_{p}=q \mu_{p}\left(p E-u_{T} \frac{\partial p}{\partial x}\right) \quad$ (16) $\quad J_{n}=q \mu_{n}\left(n E+u_{T} \frac{\partial n}{\partial x}\right)$

\section{B-Semiconductor parameters}

\section{-Generation and recombination}

The Shockley-Read-Hall generation-recombination rate is given by

$$
U_{S R H}=\frac{p n-n_{i}^{2}}{\tau_{p} n+\tau_{n} p+\tau_{0} n_{i}}
$$

The intrinsic carrier concentration can be computed by 


$$
n_{i}(T)=N_{C V}^{300}\left(\frac{T}{300}\right)^{\frac{3}{2}} \exp -\frac{q E_{G}(T)}{2 u_{T}} \quad \text { (19) Where } N_{C V}^{300}=\sqrt{N_{C}^{300} N_{V}^{300}}
$$

is the average density of states and the band gap, given by [13] .

$$
E_{G}(T)=E_{G}^{0}-\alpha \frac{T^{2}}{T+\beta}
$$

Band gap properties Si are $\mathrm{E}_{\mathrm{G}}^{0}=1.170 \mathrm{eV}, \beta=655 \mathrm{~K} \alpha=4.9 \times 10^{-4} \mathrm{eV}$ and $\mathrm{E}_{\mathrm{G}}(300 \mathrm{~K})$ $=1.12 \mathrm{eV}$

\section{-Carrier mobility}

The carrier mobility modeling is based on [14] .

$$
\mu_{p}=\mu_{p}^{300}\left(\frac{T_{R}}{T}\right)^{2.5} \quad \text { (22) } \quad \mu_{n}=\mu_{n}^{300}\left(\frac{T_{R}}{T}\right)^{2.5}
$$

Mobility properties Si are $\mu_{p}^{300}=500 \mathrm{~cm}^{2} / \mathrm{V} / \mathrm{s} \quad \mu_{n}^{300}=1000 \mathrm{~cm}^{2} / \mathrm{V} / \mathrm{s} \quad T_{R}=300 \mathrm{~K}$

\section{C-Elementary Semiconductor Regions}

\section{-Neutral regions}

The neutrality comes from the absence of charge density, which may be approximated by

$$
|\rho| \ll q \max (p, n, \Gamma)
$$

Under this assumption, (12) yields $p-n+\Gamma=0$

An N-region, is defined by $\Gamma=N_{D}>0$

In LLI, i.e., the standard case in an N-region, holes are the minority carriers, which means $n \approx N_{D} \gg p$

A P-region, is defined by $\Gamma=-N_{A}<0$

In LLI, i.e., the standard case in an P-region, electrons are the minority carriers, which means $p \approx N_{A} \gg n$

HLI is a particular case where hole and electron concentra tions are much higher than the doping concentration

$$
|\Gamma| \ll \min (n, p)
$$

which involves from (25): $\quad p \approx n$

HLI occurs in forward bias of bipolar devices.

\section{-Neutral Regions under LLI}

Consider the case of an N-region under LLI, because of (27) the drift-diffusion of the majority carriers (17) may be simplified as

$$
J_{n}=q \mu_{n}\left(N_{D} E+u_{T} \frac{\partial N_{D}}{\partial x}\right)
$$

So two (simple) cases have to be considered: 
1. A uniform doping region, i.e., $\frac{\partial N_{D}}{\partial x}=0$

2. A region with a doping concentration gradient where the gradient is not negligible.

\section{-Ohmic Regions}

An ohmic region is a neutral region with a uniform doping concentration, so in the case of a Nregion, (32) and (33) involve

$$
J_{n}=q \mu_{n} N_{D} E=-q \mu_{n} N_{D} \frac{\partial \psi}{\partial x}
$$

The integration of (34) in the region, i.e., from a to b, yields

$$
i_{n}=q \mu_{n} N_{D} E=q \mu_{n} N_{D} \frac{\psi(b)-\psi(a)}{b-a} A
$$

which defines the resistance of the ohmic N-region by (See 5) $r_{N}=\frac{W_{R}}{q \mu_{n} N_{D} A}$

and the resistance of the ohmic P-region by $r_{P}=\frac{W_{R}}{q \mu_{p} N_{A} A}$

-Neutral Regions with a Doping Gradient under LLI.

This is the case of an ohmic contact region, with an implanted or a diffused high-doping layer. In such a case, accounting eq. (11), eq. (32) may be rewritten as

$$
J_{n}=q \mu_{n}\left(-N_{D} \frac{\partial \psi}{\partial x}+u_{T} \frac{\partial N_{D}}{\partial x}\right)
$$

Because the order of magnitude of the majority current density, $J_{n}<200 \mathrm{~A} / \mathrm{cm}^{2}$

$$
\begin{array}{ll}
\left|J_{n}\right| \ll q \mu_{n} u_{T}\left|\frac{\partial N_{D}}{\partial x}\right| & \text { (39) }
\end{array}
$$

Where the contact building potential is given by [7]

$$
v_{B I}=\psi_{B}-v_{C}=\xi_{C}-\Delta \psi \quad v_{B I}=u_{T} \ln \left(\frac{N_{S S}}{n_{i}}\right)-u_{T} \ln \left(\frac{N_{S S}}{N_{B}}\right)=u_{T} \ln \left(\frac{N_{B}}{n_{i}}\right)
$$

So, in the general case

$$
v_{B I}=\psi_{B}-v_{C}=-\chi u_{T} \ln \left(\frac{N_{B}}{n_{i}}\right)
$$

With condition (31), i.e., substituting n by p, equations (16), (17), and (15) become

$$
\begin{aligned}
& J_{p}=q \mu_{p}\left(p E-u_{T} \frac{\partial p}{\partial x}\right) \quad(44) \quad J_{n}=q \mu_{n}\left(p E+u_{T} \frac{\partial p}{\partial x}\right) \\
& J=J_{n}+J_{p}=q\left(\mu_{n}+\mu_{p}\right)(p E)+q\left(\mu_{n}-\mu_{p}\right) u_{T} \frac{\partial p}{\partial x}
\end{aligned}
$$


So, substituting E using (55), the following is obtained

$$
J_{p}=\frac{\mu_{p}}{\mu_{n}+\mu_{p}} J-q D \frac{\partial p}{\partial x} \quad \text { (47) And } J_{n}=\frac{\mu_{n}}{\mu_{n}+\mu_{p}} J+q D \frac{\partial p}{\partial x}
$$

Where $\quad D=\frac{2 \mu_{n} \mu_{p}}{\mu_{n}+\mu_{p}} u_{T}$

is the ambipolar diffusion coefficient.Equation (55) may be rewritten as

$$
E=\frac{J}{q\left(\mu_{n}+\mu_{p}\right) p}-\frac{\mu_{n}-\mu_{p}}{\mu_{n}+\mu_{p}} u_{T} \frac{1}{p} \frac{\partial p}{\partial x}
$$

Integrating this last equation from 0 to $\mathrm{W}_{\mathrm{N}}(56)$ yields to the drop voltage across the plasma region

$$
v_{N}=R_{D} i_{p n}+v_{D} \quad \text { (51) Where } \quad R_{D}=\int_{0}^{W_{N}} \frac{d x}{q\left(\mu_{n}+\mu_{p}\right) p A}
$$

\begin{tabular}{|l|l|l|}
\hline Symbol & Definition & Physical domain \\
\hline $\mathrm{N}_{\mathrm{B}}$ & Doping concentration at the space charge region boundary & Concentration \\
\hline $\mathrm{V}_{\mathrm{BI}}$ & Contact to Space Charge Region building potential & Voltage \\
\hline $\mathrm{X}$ & Doping Concentration Index, -1 for N-type and 1 for a P-type & - \\
\hline $\mathrm{N}_{\mathrm{SS}}$ & Doping concentration at the contact & Concentration \\
\hline $\mathrm{v}_{\mathrm{c}}$ & Electric potential at the metallic contact & Voltage \\
\hline$\psi_{\mathrm{S}}$ & Electric potential (mid-gap potential) at the contact boundary & Voltage \\
\hline$\xi_{\mathrm{c}}$ & Contact building potential & Voltage \\
\hline$\psi_{\mathrm{B}}$ & $\begin{array}{l}\text { Electric potential (mid-gap potential) at the space charge region } \\
\text { boundary }\end{array}$ & Voltage \\
\hline
\end{tabular}

Table 10: Symbols of a DGN region in LLI.

$$
v_{D}=\frac{\mu_{n}-\mu_{p}}{\mu_{n}+\mu_{p}} u_{T} \ln \left(\frac{p(a)}{p(b)}\right)
$$

-Case of the linear approximation (Hefner).

In this case, $\quad p(t, x) \simeq N_{D}+x \frac{p_{1}(t)}{w_{N}(t)}$

The excess charge is given by

$$
Q_{P}(t)=\int_{0}^{w_{x}(t)} q\left(p(t, x)-N_{D}\right) A d x
$$

Using (54), the following is obtained $Q_{P}(t)=q A \frac{p_{1}(t)}{w_{N}(t)} \int_{0}^{w_{N}} x d x=\frac{q A p_{1}(t) w_{N}(t)}{2}$

Defining the ratio $b=\frac{\mu_{p}}{\mu_{n}}$

With (51), the following is obtained $i_{p}=J_{p} A=\frac{b}{1+b} i-q D A \frac{\partial p}{\partial x}$

Using the same approximation, as Hefner did, $\quad i=i_{p}=-q(1+b) D A \frac{\partial p}{\partial x}$ 


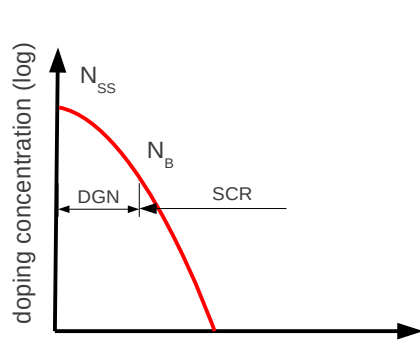

a

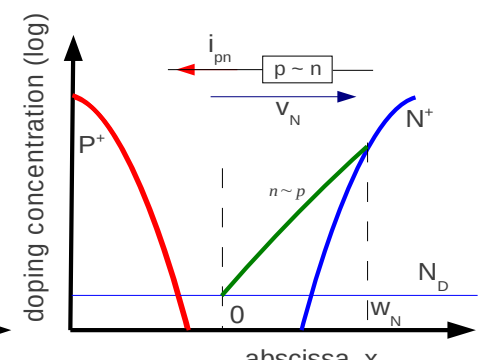

C

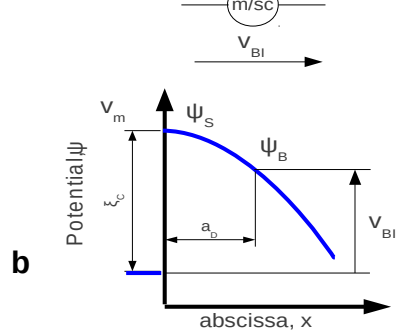

Fig. 7: a) Typical doping profile in an ohmic contact semiconductor region, b) typical electric potential in a DGN region, c) typical plasma profile and the associated symbol.

And using (54), the following is obtained

$$
i_{p n}=-i_{p}=q(1+b) D A \frac{p_{1}}{w_{N}}
$$

Combining (59) and (60), the classical expression from Hefner's paper is obtained

$$
\begin{aligned}
& i_{p n}=\frac{2(1+b) D Q_{p}}{w_{N}^{2}}=\frac{4 D_{p} Q_{p}}{w_{N}^{2}} \\
& R_{D}=\frac{1}{q\left(\mu_{n}+\mu_{p}\right) A N_{D}} \int_{0}^{w_{x}} \frac{d x}{1+\frac{p_{1} X}{N_{D} w_{N}}} \quad R_{D}=\frac{1}{q\left(\mu_{n}+\mu_{p}\right) A N_{D}} \frac{N_{D} w_{N}}{p_{1}} \ln \left|1+\frac{p_{1}}{N_{D}}\right|
\end{aligned}
$$

Some reference values are needed to simplify expressions. So, the reference current for HLI is defined by $i_{p n}^{0}=q(1+b) D A \frac{N_{D}}{w_{N}}$

and the standardized maximal carrier concentration in the plasma region by

$$
\rho_{p n}=\frac{i_{p n}}{i_{p n}^{0}}=\frac{p_{1}}{N_{D}}
$$

And the reference resistance by $R_{D D}=\frac{W_{B}}{q\left(\mu_{n}+\mu_{p}\right) A N_{D}}$

If fast transients are excluded, the width of the plasma region is similar to the epitaxial layer width $w_{N}(t) \sim W_{B}$

So equation (62) may be rewritten as $R_{D}=R_{D D} \frac{\ln \left|1+\rho_{p n}\right|}{\rho_{p n}}$

However, this expression yields a numerical exception when $i_{p n}=0$, so the convenient expression is given by, $R_{D}=R_{D D} \frac{\ln \left|1+\rho_{p n}\right|}{1+\rho_{p n}}$

That has no consequence when $i_{p n}$ is small because $R_{D}$ is multiplied by $i_{p n}$ in equation (57). 
From (53), (63), and (66), it comes $v_{D}=\frac{\mu_{n}-\mu_{p}}{\mu_{n}+\mu_{p}} u_{T} \ln \left(\frac{N_{D}+p_{1}}{N_{D}}\right)=\frac{1-b}{1+b} u_{T} \ln \left(1+\rho_{p n}\right)$

\section{-Space Charge Regions}

A space charge region is a region where the condition (24) is not satisfied, i.e., a space charge region is not neutral. In depletion mode, the carrier concentrations are negligible with respect to the doping concentration, and for an abrupt junction, the barrier height is classically given by

$$
u_{B}=\frac{q N_{D} w^{2}}{2 \epsilon}
$$

In depletion mode, a well-known property of a space charge region is that the pn product is fairly constant, i.e., independent of the space.

$$
\mathrm{p}_{\mathrm{N}} \mathrm{N}_{\mathrm{D}}=\mathrm{n}_{\mathrm{P}} \mathrm{N}_{\mathrm{A}}=\mathrm{n}_{\mathrm{i}}^{2} \exp \frac{\mathrm{v}}{\mathrm{u}_{\mathrm{T}}}=\mathrm{N}_{\mathrm{A}} \mathrm{N}_{\mathrm{D}} \exp -\frac{\mathrm{u}_{\mathrm{B}}}{\mathrm{u}_{\mathrm{T}}}
$$

The standard analysis assumes an asymmetric abrupt junction, i.e., $\quad N_{A} \gg N_{D}$

The diffusion of minority carrier at the boundary of the space charge region yields the classical diffusion current (mainly the diffusion current of holes in the N-side)

$$
\mathrm{i}_{\mathrm{D}}=\frac{\mathrm{Q}_{\mathrm{p}}}{\mathrm{T}_{\mathrm{p}}}=\frac{\mathrm{qA}\left(\mathrm{p}_{\mathrm{N}}-\mathrm{p}_{0}\right) \mathrm{L}_{\mathrm{Dp}}}{\mathrm{T}_{\mathrm{P}}}
$$

Where the equilibrium hole concentration on the N-side is given by $\mathrm{p}_{0}=\frac{\mathrm{n}_{\mathrm{i}}^{2}}{\mathrm{~N}_{\mathrm{D}}}$

and $\mathrm{L}_{\mathrm{Dp}}=\mathrm{D}_{\mathrm{p}} \tau_{\mathrm{p}}=\mu_{\mathrm{p}} \mathrm{u}_{\mathrm{T}} \tau_{\mathrm{p}}$

In the case of an asymmetric junction, the current diffusion of electrons on the P-side is negligible. Notice that from (73) and (71) the standard Shockley's equation may be obtained

$$
\mathrm{i}_{\mathrm{D}}=\mathrm{i}_{\mathrm{S}}\left(\exp -\left(\frac{\mathrm{v}}{\mathrm{u}_{\mathrm{T}}}\right)-1\right) \quad \text { (76) With } \mathrm{i}_{\mathrm{S}}=\frac{\mathrm{qA} \mathrm{A}_{\mathrm{Dp}} \mathrm{n}_{\mathrm{i}}^{2}}{\mathrm{~T}_{\mathrm{P}} \mathrm{N}_{\mathrm{D}}}\left(\mathrm{p}_{\mathrm{N}}-\mathrm{p}_{0}\right)
$$

However, in a regional approach, the diffusion current is preferentially computed from the local voltage drop in the space charge region, $\mathrm{u}_{\mathrm{B}}$, instead of the device voltage drop, $\mathrm{v}$.

$$
\mathrm{i}_{\mathrm{D}}=\mathrm{i}_{\mathrm{p} 0}\left(\exp -\left(\frac{\mathrm{u}_{\mathrm{B}}}{\mathrm{u}_{\mathrm{T}}}\right)-\exp \left(\frac{\mathrm{v}_{\mathrm{BI}}}{\mathrm{u}_{\mathrm{T}}}\right)\right) \quad \text { (78) With } \mathrm{i}_{\mathrm{p} 0}=\frac{\mathrm{qA} \mathrm{L} \mathrm{L}_{\mathrm{Dp}} \mathrm{N}_{\mathrm{A}}}{\mathrm{T}_{\mathrm{P}}}
$$

A generation current exists in the space charge region. It corresponds to the generation of holes and electrons inside the space charge region when it is large.

In most cases, the generation current represents the main part of the leakage current of a PNjunction in reverse bias. It is given by $\mathrm{i}_{\mathrm{G}}=\frac{\mathrm{qn}_{\mathrm{i}} \mathrm{A}}{\mathrm{T}_{0}}\left(\mathrm{w}-\mathrm{w}_{0}\right)$

The $\mathrm{w}_{0}$ term has been added to ensure that the generation current equals zero at equilibrium, i.e., when $\mathrm{w}=\mathrm{w}_{0}$.

Finally, the total (leakage) current through the space charge region is given by

$$
\mathrm{i}_{\mathrm{pn}}=\mathrm{i}_{\mathrm{G}}-\mathrm{i}_{\mathrm{D}}
$$




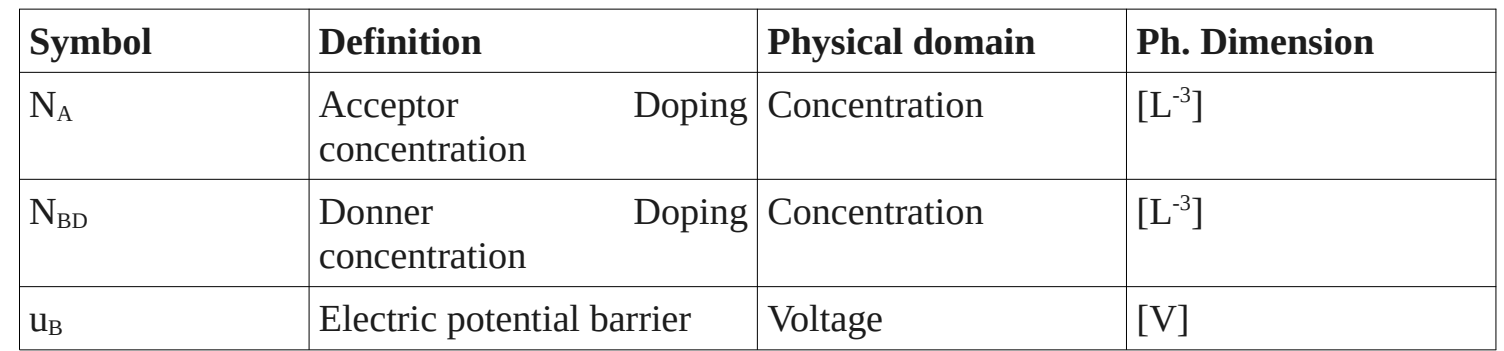

Tableau 11 :Parameters for the space charge region model.

\section{MOSFET Channel Model}

The 2-Kp model proposed by Hefner [1]

$$
\begin{aligned}
& i_{C H}=0 \quad \text { if } V_{G S}<V_{T} \\
& i_{C H}=K_{p l i n} \frac{\left(V_{G S}-V_{T}\right) V_{d s}-\frac{K_{p l i n} V_{d s}^{2}}{2 \mathrm{~K}_{p s a t}}}{2\left[1+\theta\left(V_{G S}-V_{T}\right)\right]} \\
& \text { if } V_{d s} \leqslant\left(V_{G S}-V_{T}\right) \frac{K_{p s a t}}{K_{p l i n}} \\
& i_{C H}=K_{p s a t} \frac{\left(V_{G S}-V_{T}\right)^{2}}{2\left[1+\theta\left(V_{G S}-V_{T}\right)\right]} \quad \text { if } V_{d s}>\left(V_{G S}-V_{T}\right) \frac{K_{p s a t}}{K_{\text {plin }}}
\end{aligned}
$$

\begin{tabular}{|l|l|l|}
\hline Symbol & Definition & Units \\
\hline \multicolumn{1}{|c|}{$K_{p}^{\text {lin }}$} & Transconductance in linear mode & $\mathrm{AV}^{-2}$ \\
\hline$K_{p}^{\text {sat }}$ & Transconductance in saturation mode & $\mathrm{AV}^{-2}$ \\
\hline $\mathrm{V}_{\mathrm{T}}$ & Threshold Voltage & $\mathrm{V}$ \\
\hline$\theta$ & Mobility modulation factor & $\mathrm{V}^{-1}$ \\
\hline
\end{tabular}

Table 11: Parameters of a MOSFET channel region. 